\title{
Identification of Student Lifestyle Characteristics Associated with Training Choices to Drive Targeted Admissions in Veterinary Medicine
}

\author{
Margaret V. Root Kustritz, Erin Malone' ${ }^{1}$, Aaron Rendahl ${ }^{2}$ \\ Department of Veterinary Clinical Sciences, College of Veterinary Medicine, University of Minnesota, Minneapolis, Minnesota, USA, 'Department of Veterinary \\ Population Medicine, College of Veterinary Medicine, University of Minnesota, Minneapolis, Minnesota, USA, ${ }^{2 D e p a r t m e n t ~ o f ~ V e t e r i n a r y ~ a n d ~ B i o m e d i c a l ~ S c i e n c e s, ~}$ \\ College of Veterinary Medicine, University of Minnesota, Minneapolis, Minnesota, USA
}

\section{Abstract}

Background: There is an identified need for practicing veterinarians with a focus on food animal work in the United States. Students at the University of Minnesota College of Veterinary Medicine track by species (food animal, equine, mixed, and small animal) or discipline (research) in the latter part of their training. Identification of life experiences that are associated with students choosing the food animal track would permit the college to better target admissions to meet societal needs. Aims and Objectives: To identify lifestyle characteristics and activities associated with choice of the food animal track and to evaluate how student choice of track varies across their training. Materials and Methods: Students from three consecutive classes were surveyed to identify factors influencing track choice. Fisher's test was used to compare data and Clopper-Pearson "exact" confidence intervals computed. Results: Students who declared interest in the 1st year in small animal, equine, or food animal as a track were highly likely to choose that at their final track later in the curriculum. Eightyfive percent of students in a food animalfocused early admission track chose the food animal track; the remainder chose the mixed track with cattle as one of their species of interest. Students were more likely to choose the food animal track if their undergraduate major was animal science, if they grew up in a rural area, lived on a farm, were in 4H or were in Future Farmers of America, or had shown or worked horses or cattle, or shadowed a large animal veterinarian. Students valued mentoring from within the college and from outside veterinarians. Conclusions: Knowledge of how students choose their tracks will permit the college better to promote admissions of students who are more likely to track food animal and to plan for adequate clinical year experiences for all students.

Keywords: Admissions, track, veterinary medicine

\section{INTRODUCTION}

There is a documented need for veterinarians who provide services for food animals (cattle, swine, small ruminants, and poultry) in rural areas in the United States. "The reduced number of rural food-animal veterinarians has left a gap in animal care and raises concerns about the level of animal disease surveillance in the field, which is critical to the prompt detection of outbreaks with potentially massive economic consequences, not to mention public health threats such as H5N1 avian influenza."[1]

The curriculum at the University of Minnesota College of Veterinary Medicine (UMN CVM) permits students in their clinical year of training to track by species. Tracks from which

\begin{tabular}{|l|l|}
\hline \multicolumn{2}{|c|}{ Access this article online } \\
\hline Quick Response Code: & Website: \\
\hline & www.ehpjournal.com \\
\cline { 2 - 2 } & \\
\hline
\end{tabular}

they choose are equine, food animal, mixed animal, research, and small animal. Some argue that permitting students to track limits graduates' career options and may make it more difficult for students to achieve licensure. Others argue that students who are permitted to track can graduate with greater

Address for correspondence: Dr. Margaret Viola Root Kustritz, Department of Veterinary Clinical Sciences, College of Veterinary Medicine, University of Minnesota, 1352 Boyd Avenue, St. Paul,

Minnesota 55108, USA.

E-mail: rootk001@umn.edu

This is an open access journal, and articles are distributed under the terms of the Creative Commons Attribution-NonCommercial-ShareAlike 4.0 License, which allows others to remix, tweak, and build upon the work non-commercially, as long as appropriate credit is given and the new creations are licensed under the identical terms.

For reprints contact: reprints@medknow.com

How to cite this article: Kustritz MV, Malone E, Rendahl A. Identification of student lifestyle characteristics associated with training choices to drive targeted admissions in veterinary medicine. Educ Health Prof 2020;3:70-6.

Submission: 13.02 .2020

Acceptance: 12.03 .2020

Revision: 19.02 .2020 Web Publication: 27.07.2020 
competence in their species or discipline of interest and that tracking better permit colleges to use their resources wisely and to meet the needs of their region. ${ }^{[2]}$ Because there is a need for food animal veterinarians, it would be beneficial for the UMN CVM to be able to identify at admissions which applicants would be most likely to track food animal and most likely move on to work as rural food animal practitioners, addressing the need stated above.

The UMN CVM has an early admission program to promote food animal training and career choice (VetFAST) ${ }^{[\mathrm{a}]}$ students who gain admission through the VetFast program are not required to complete their training in the food animal track. Students may choose their track because of comfort with

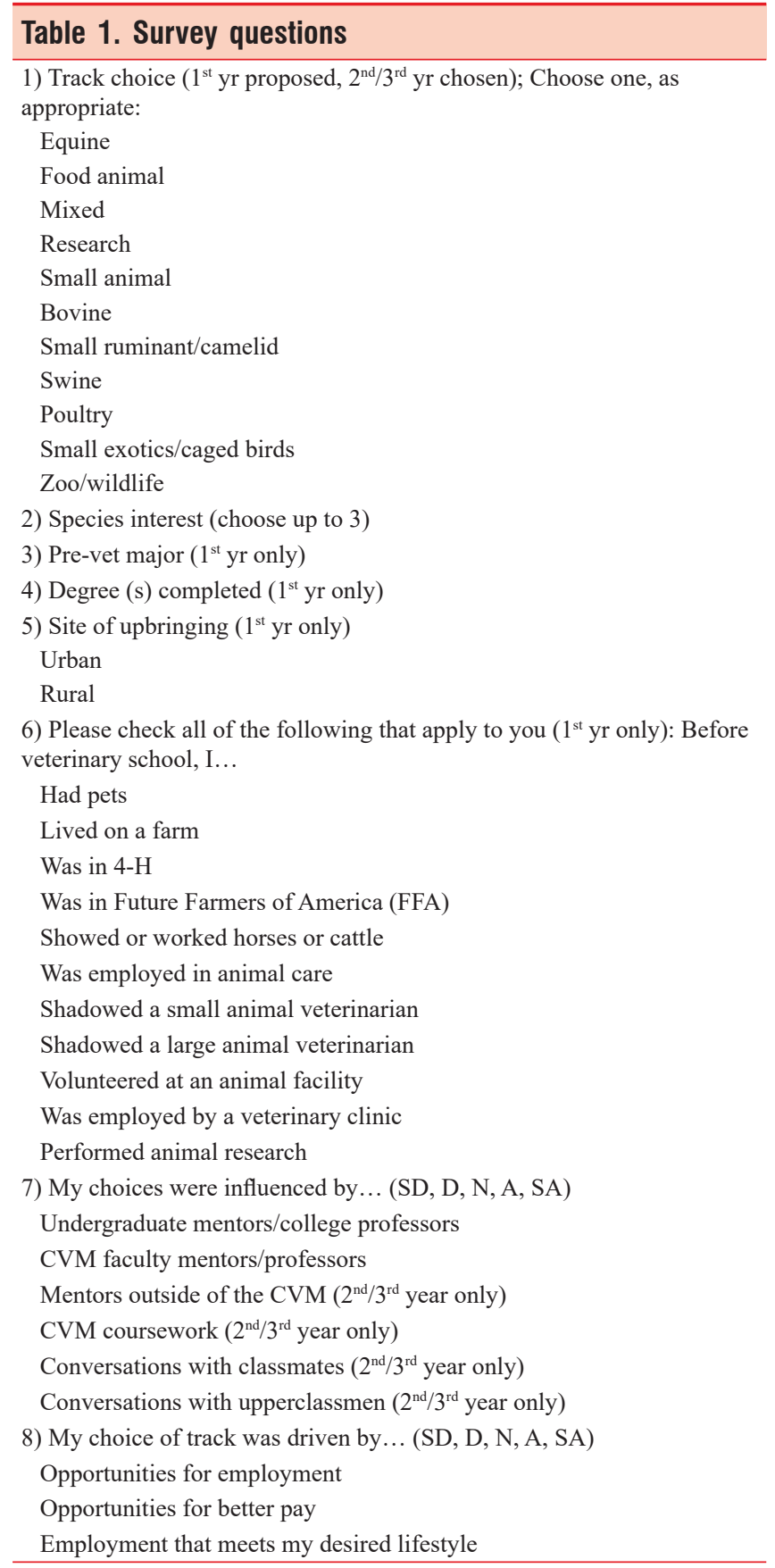

their species of interest and perceived employment or pay opportunities. ${ }^{[3]}$ Mentors and personal experiences shape this decision. ${ }^{[3]}$ At the University of California-Davis, background experience was the overwhelming factor guiding student decision-making around tracks, with choice of a track to better meet desired lifestyle the second most important factor. ${ }^{[3]}$

Research questions addressed in this study were:

- What factors drive choice of academic track within the veterinary curriculum?

- How frequently and in what way do students choices about track vary over the course of their veterinary training?

\section{Materials and Methods}

The study was approved by an institutional review board (study number 1502E62842). Students from three consecutive veterinary classes were surveyed during fall semester of their $1^{\text {st }}$ year and again later in the curriculum (either late in year 2 or early in year 3) as they determined their final track choice [Table 1]. Data were removed from the data set if there were no matching data from both surveys.

To test if the proportion entering each of the five tracks was different between those answering yes and those answering no for each question, Fisher's test was performed on each $2 \times 5$ table individually. To further explore for which track the proportions differed, Fisher's test for the number choosing each track compared with all other tracks was also performed for each question. Since the overall Fisher's test controlled the experiment-wise error rate for each question, and these subtests are correlated within each question, no further correction for multiple comparisons was done. In addition, Clopper-Pearson "exact" confidence intervals for each proportion were computed.

\section{REsults}

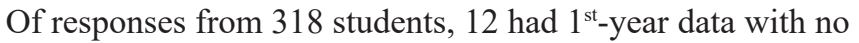
later data, and 56 had later data with no $1^{\text {st }}$-year data; data from these 68 students were removed from the data set. Those students who had $1^{\text {st }}$-year data and no later data generally had left the program after the $1^{\text {st }}$ year for academic or personal reasons or had entered a dual degree program and missed data collection from the Doctor of Veterinary Medicine (DVM) class cohorts as they were completing their $\mathrm{PhD}$. Those who had no $1^{\text {st }}$-year data but had later data either chose not to complete the survey when they were in the $1^{\text {st }}$ year or came into the DVM cohort after sampling had begun, for example, as they re-entered the DVM program after having taken time off to complete a $\mathrm{PhD}$. Of the remaining 250 responses, 92 were from the class of 2019, 73 from the class of 2020, and 85 from the class of 2021.

There were six students from the class of 2019, five from the class of 2020, and four from the class of 2021 that were admitted through the VetFAST system. Matching data were 
available for 13 of these students. Eleven tracked food animal and two tracked mixed with one pursuing work in cattle and small animals and the other pursuing work in cattle and horses.

The percentage of respondents in each track by class in the $1^{\text {st }}$ year and later in the curriculum is shown in Figure 1. The overall percentage of respondents in each track in the $1^{\text {st }}$ year and later in the curriculum is shown in Figure 2. When tracked by a student, the percentage who stayed in the track they had chosen in the $1^{\text {st }}$ year and disposition of those who changed tracks is shown in Table 2.

Overall, students who stated that they intended to track small animal, food animal, or equine in the $1^{\text {st }}$ year were highly likely to choose that as their final track. Students who chose mixed or research tracks in the $1^{\text {st }}$ year were less likely to choose that as their final track.

Species interests of students initially and later in the curriculum are shown in Figure 3. Students were permitted to choose up to three species of interest.

Species interest did not change dramatically except for a decline in zoo animal/wildlife interest and an increased interest in small exotics and caged birds.

The majority of respondents had completed a bachelor's degree $(90.4 \%)$ and a small number had completed both a bachelor's degree and a master's degree $(4.0 \%)$. One student had completed an associate's degree and the rest had not completed any undergraduate degree before beginning veterinary school. Biology/biological sciences was the most common preveterinary major (43.6\% of respondents), with animal science second most common (36.4\%). Other science-based majors (5.6\%) and humanities (10.4\%) were the other categories of preveterinary majors completed by the respondents. Ten students $(4.0 \%)$ had majors in more than one of these categories.

The majority of respondents had been raised in an urban area $(62.8 \%)$. Percentages with various life experiences are shown in Table 3.

Plots in Figure 4 show the percentage that chose each track for each answer (yes [teal] or no [rust]) for each question and with $95 \%$ confidence intervals as bars. The $P$ values are for overall tests that this question was associated with the track they chose. The stars to the left show significance for the individual tracks separately, not corrected for multiple comparisons, with $*<0.05$, and $* *<0.01$ [Figure 4]. The data sets were combined from the three classes for analysis.

Preveterinary major was associated with track choice, with those students who received a bachelor's degree in animal science more likely to track food animal and less likely to track small animal. The association with track for students who completed bachelor's degrees in biology, other life sciences, or liberal arts majors before entering veterinary school was not significant at the 0.05 level.

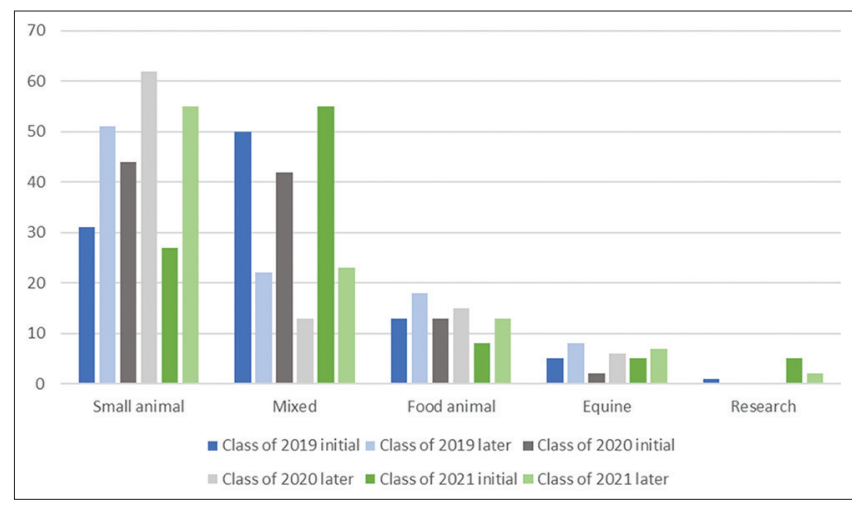

Figure 1: Percentage of respondents in each track by in the $1^{\text {st }}$ year and later in the curriculum

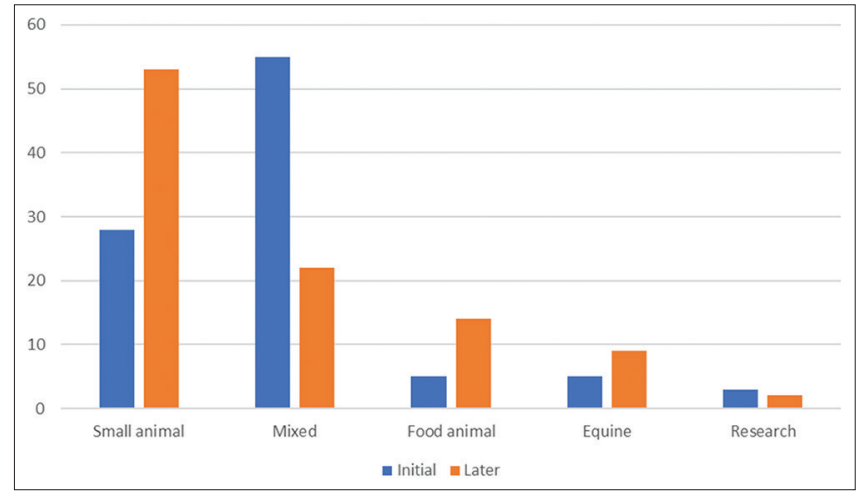

Figure 2: Overall percentage of respondents by track in the $1^{\text {st }}$ year and later in the curriculum

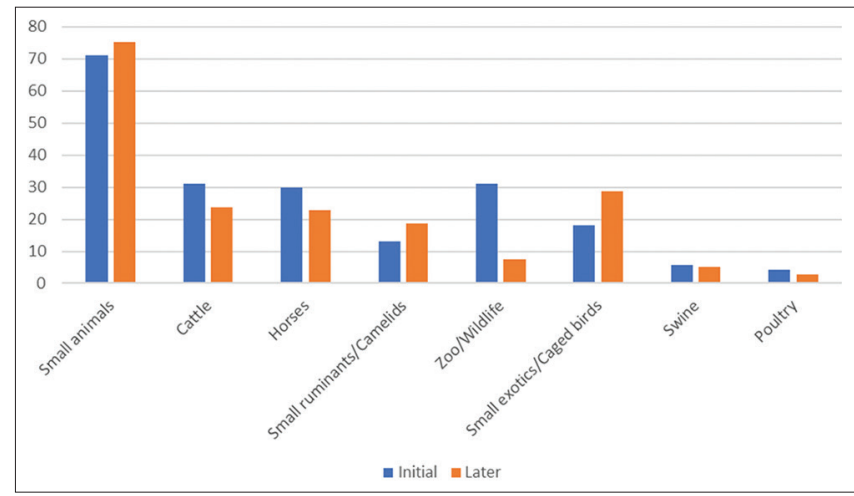

Figure 3: Species interests of all students initially and later in the curriculum

Those students who grew up in a rural area, lived on a farm, were in 4-H, or were in Future Farmers of America (FFA) were much more likely to choose the food animal track and much less likely to choose the small animal track (overall $P<0.0001$ and difference between tracks of $<0.01$ ). Students who had shown or worked horses or cattle, or shadowed a large animal veterinarian, were more likely to track food animal and less likely to track small animal.

Respondents also were asked their perception of what most affected their track choice [Table 4]. Some questions were 
Kustritz, et al.: Drivers for track change decision-making

\begin{tabular}{|c|c|c|}
\hline Description & $\begin{array}{l}\text { Percentage staying } \\
\text { in initial track (\%) }\end{array}$ & $\begin{array}{l}\text { Of those leaving initial track, percentage } \\
\text { moving into each other track }\end{array}$ \\
\hline $\begin{array}{l}\text { Percentage choosing small animal track in the } \\
1^{\text {st }} \text { year that remained in small animal track }\end{array}$ & 100 & - \\
\hline $\begin{array}{l}\text { Percentage choosing mixed track in the } 1^{\text {st }} \\
\text { year that remained in mixed track }\end{array}$ & 37.2 & $\begin{array}{l}67.4 \% \text { to small animal } \\
17.4 \% \text { to food animal } \\
12.8 \% \text { to equine } \\
2.3 \% \text { to research }\end{array}$ \\
\hline $\begin{array}{l}\text { Percentage choosing food animal track in the } \\
1^{\text {st }} \text { year that remained in food animal track }\end{array}$ & 91.3 & $\begin{array}{l}50.0 \% \text { to small animal } \\
50.0 \% \text { to mixed }\end{array}$ \\
\hline $\begin{array}{l}\text { Percentage choosing equine track in the } 1^{\text {st }} \\
\text { year that remained in equine track }\end{array}$ & 84.6 & $100.0 \%$ to mixed \\
\hline $\begin{array}{l}\text { Percentage choosing research track in the } 1^{\text {st }} \\
\text { year that remained in research track }\end{array}$ & 25.0 & $\begin{array}{l}83.4 \% \text { to small animal } \\
16.6 \% \text { to mixed }\end{array}$ \\
\hline
\end{tabular}

Table 3: Percentage of students with various lifestyles/ experiences

\begin{tabular}{lc}
\hline Experience & $\begin{array}{c}\text { Percentage responding } \\
\text { positively (\%) }\end{array}$ \\
\hline Had a pet & 96.4 \\
Lived on a farm & 19.6 \\
Were in 4-H & 18.4 \\
Were in FFA & 9.6 \\
Had shown or worked with horses or cattle & 33.6 \\
Had been employed in animal care during & 67.2 \\
upbringing (including self-employed) & \\
Had shadowed a small animal veterinarian & 79.2 \\
Had shadowed a large animal veterinarian & 53.2 \\
Had volunteered with hands-on work at a & 73.2 \\
veterinary facility & \\
Had been employed by a veterinary clinic & 71.6 \\
Had participated in animal research & 38.0 \\
\hline
\end{tabular}

FFA: Future Farmers of America

asked only later in the curriculum.

\section{DISCUSSION}

Students in all three classes in this study showed the same pattern when considering likelihood of students changing track from the $1^{\text {st }}$ year to later in the curriculum, with small animal track and food animal track students generally staying with that track choice and a large percentage of undecided students choosing the mixed track in the $1^{\text {st }}$ year and later moving to another track. The increase in small animal tracking students demonstrated in this study supports other published work. ${ }^{[4]}$ Over half of the class tracks small animal every year and about $15 \%$ of the class tracks food animal. There is variability in the percentage that tracks mixed and the inherent flexibility of our mixed track requirements can make scheduling of students in desired rotations challenging.

Students were surveyed early in the curriculum. Some of the data collected also are collected within the centralized admission system (Veterinary Medical College Application Service American Association of Veterinary Medical Colleges, https://www.aavmc.org/students-applicants-and-advisors/ veterinary-medical-college-application-service.aspx). For this study, we chose to use survey data generated by the college because we encourage students to use a survey during the $1^{\text {st }}$ year of the curriculum to start them thinking very early in their training about their eventual track choice. The use of this survey also minimizes likelihood that students will complete survey information in an attempt to look good to various colleges while seeking admission.

The UMN CVM has historically used the VetFAST program to promote student choice in the food animal track. The college puts no pressure on students when they choose their tracks late in the $2^{\text {nd }}$ year or early in the $3^{\text {rd }}$ year. It is gratifying to see that the majority of students who enter the program through VetFAST choose the food animal track or choose mixed with an emphasis on cattle.

Change in track and subsequently in career choice based on curricular offerings was identified as a driver in over $40 \%$ of students in this study. One study showed that 17 of 26 students had a change in proposed career after having completed a course on veterinary careers. ${ }^{[5]}$ Veterinary students largely are taught by specialists who may have limited knowledge of the day-to-day life of general practitioners in various career paths, and this may lead to a "hidden curriculum" where students are inadvertently taught to believe certain things about various opportunities. ${ }^{[6]}$ There is great value in curricular offerings to ensure students who understand the breadth of opportunities available to them as veterinary graduates and how various options will help them achieve their financial and lifestyle goals. ${ }^{[7]}$

In general, species interest was more stable with the exception of zoo/wildlife and small exotics/caged birds. The latter was a surprising result. While information about small exotics and caged birds is offered in one core course and one elective, the UMN CVM does not have a clinical service for small exotics or caged birds, and students have limited opportunities to learn about these species on campus. Despite the UMN CVM not offering this specialty training, student interest in these species increases during their training. The decline in interest in zoo 


\begin{tabular}{|c|c|c|}
\hline \multirow[t]{2}{*}{ Statement - “...” influenced my choice of track } & \multicolumn{2}{|c|}{ Percentage responding agree or strongly agree } \\
\hline & $1^{\text {st }}$ year & Later in the curriculum \\
\hline My upbringing prior to college... & 75.6 & 72.8 \\
\hline Mentors/college professors during my undergraduate training... & 30.0 & 25.6 \\
\hline Mentors/college professors in the veterinary curriculum.... & 20.0 & 37.2 \\
\hline Mentors outside of the XX & - & 50.8 \\
\hline Coursework in the veterinary curriculum... & - & 40.8 \\
\hline Discussion with members of my class... & - & 34.8 \\
\hline Discussion with upperclassmen... & - & 31.3 \\
\hline Belief that my chosen track will lead to more employment opportunities... & 45.6 & 36.8 \\
\hline Belief that my chosen track will lead to jobs that pay better... & 25.6 & 23.2 \\
\hline Belief that my chosen track will lead to jobs that better match the lifestyle I desire... & 65.6 & 62.8 \\
\hline
\end{tabular}

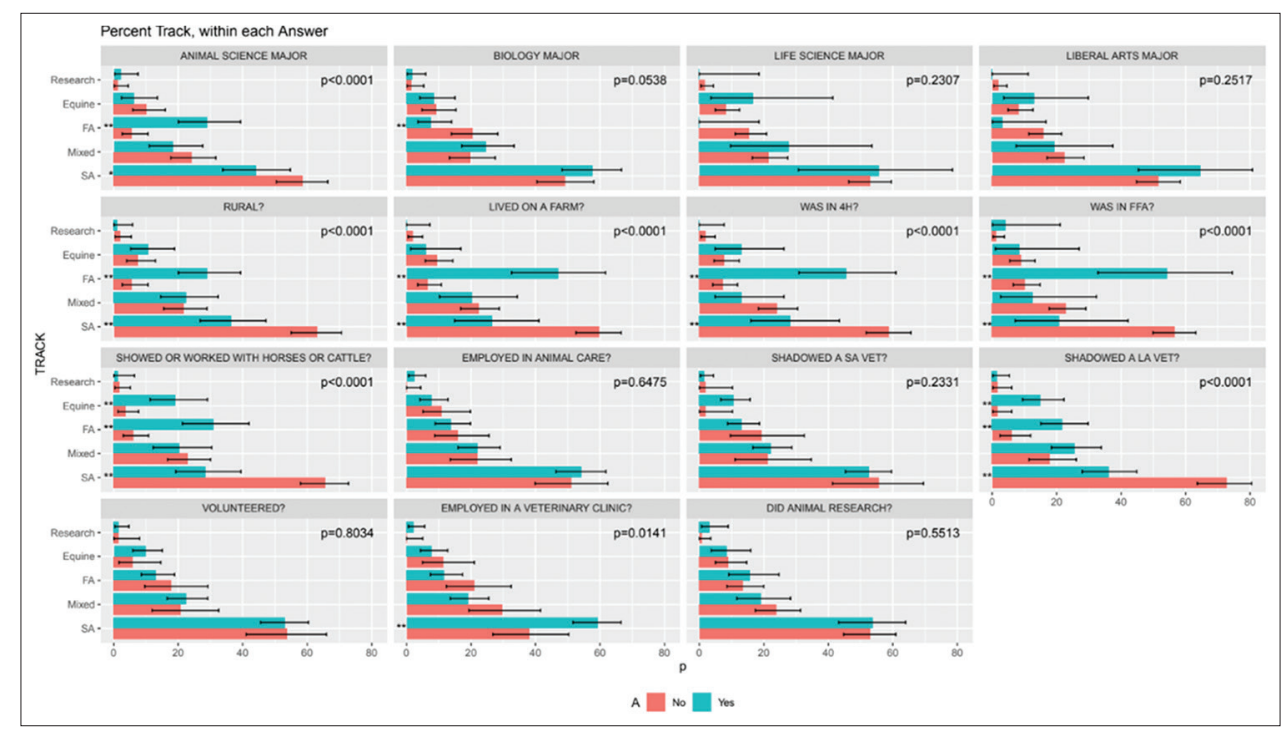

Figure 4: Association between lifestyle/experiences and chosen track

and wildlife species likely is a reflection of growing knowledge of how difficult it can be to find employment working with these species.

Students were more likely to choose the food animal track if their undergraduate major was animal science, if they grew up in a rural area, lived on a farm, were in 4-H or were in FFA, or had shown or worked horses or cattle, or shadowed a large animal veterinarian. These were not surprising findings. This is similar to findings from other studies in which those students most likely to enter mixed or food animal practice had been raised in a community with a population of 10,000 or less, had lived on a farm, or had past life experience in food animal production. ${ }^{[4,8-10]}$ One study of Canadian veterinarians supported choice of food animal track and employment if candidates were raised in a small town and if they had an undergraduate degree in agriculture but did not show any correlation with participation in 4-H. ${ }^{[1]}$ This is not surprising, given the broad nature of 4-H. Veterinary students participating in an 8-week dairy production medicine course were more likely to have sought out this experience if they had participated in youth livestock activities, worked or lived on a livestock facility, and had taken animal science courses as undergraduates. ${ }^{[12]} \mathrm{A}$ concern has been raised that if living on a farm or in a rural area is a driver of veterinary students toward food animal medicine, it will become increasingly difficult as fewer and fewer people live on farms in the United States. ${ }^{[13]}$ Similarly, schools of veterinary medicine must be careful to ensure that students receive enough food animal training to foster interest in career choice. ${ }^{[13]}$ Some studies have shown that classmates, courses in the veterinary curriculum, and mentoring from faculty are drivers toward career choice. ${ }^{[13]}$ Results from this study support that finding.

The UMN CVM is in partnership with South Dakota State University in a $2+2$ program that will focus on rural food animal practice. Accurate knowledge of what drivers push students toward choosing the food animal track will be valuable in helping shape admission criteria for that program.

It is interesting that students can see how their upbringing greatly influenced their track choice. Survey comments included intention to return home, especially if they knew veterinarians were scarce there; acknowledgment that limited 
opportunities during their upbringing due to financial concerns likely shaped their choices now; and how the opportunities they were permitted to pursue by their parents helped them get into veterinary school and continue to shape their development.

It is important to see how much value students place on veterinary mentors from outside of the College of Veterinary Medicine (CVM); this helps our alumni association understand how best graduates can serve current students by providing mentoring opportunities. One analysis of university graduates looked at the influence of happenstance (unplanned events that measurably alter one's behavior) on career choices and identified as the primary driver relationships with professors, advisors, and employers. ${ }^{[14]}$ In the midst of a shortage of food animal veterinarians, it may be more difficult for students to find those mentors in the field, worsening the problem. ${ }^{[15]}$ Faculty mentoring is limited by availability of time for faculty and students to meet and unwillingness of students to seek out faculty; creation of online mentoring tools may be one way to try to meet this demand. ${ }^{[16]}$

Students also appear to be very interested in finding work that helps them meet their overall life goals, similar to what was described in the UC-Davis study. ${ }^{[3]}$ In a study specifically considering food animal work, $20 \%$ of students changed career path while in school, looking for better pay or work that better met their needs for work-life balance. ${ }^{[17]}$ This will encourage the UMN CVM to continue to provide students with professional development training and preceptorship opportunities, so they more completely understand career paths available to them.

A primary deficiency of this study is that it ends at track choice and does not follow students beyond graduation to see if they achieve employment that meets their chosen lifestyle and are satisfied with the training they received. Alumni surveys at the UMN CVM suggest that most students choose employment that matches their track but response rates on alumni surveys are not high, skewing that data, perhaps toward those who are happy and therefore more willing to respond, and alumni survey data is anonymous. A study comparing a nontracking curriculum to a tracked curriculum demonstrated that graduates from both systems showed a great diversity in employment after graduation and that a majority of respondents from both programs felt that they had training that permitted them to get up to speed at any job within a month or less. ${ }^{[18,19]}$ The UMN CVM continues to search for effective ways to track our graduates and determine from them the absolute outcome of their training.

\section{Conclusions}

Students who are more likely to track food animal and less likely to track small animal are those with a rural or farm background, those who participated in large animal activities, and those who earned a bachelor's degree in animal science. Specific emphasis on this background can be added to admission criteria to populate classes with more food animal track students and therefore educate a larger workforce to meet this need regionally and nationally. Students who specify mixed or research as their chosen track in the $1^{\text {st }}$ year may benefit from mentoring to help them determine earlier in their training their likely final choice of track. This will improve planning for the student and the college.

\section{Financial support and sponsorship}

Nil.

\section{Conflicts of interest}

There are no conflicts of interest.

\section{RefEREnCES}

1. National Research Council. Workforce Needs in Veterinary Medicine. Washington, D.C: The National Academies Press; 2012.

2. Bailey J, Hagele WC, Leung D, Lofstedt J, Radostits OM, Sandals D. CVMA Task Force on "education, licensing, and the expanding scope of veterinary practice". Can Vet J 2002;43:845-54.

3. Chigerwe M, Boudreaux KA, Ilkiw JE. Factors affecting track selection by veterinary professional students admitted to the school of veterinary medicine at the University of California, Davis. J Vet Med Educ 2010;37:154-8.

4. Heath TJ. Longitudinal study of career plans and directions of veterinary students and recent graduates during the first five years after graduation. Aust Vet J 1998;76:181-6.

5. Fish RE, Griffith EH. Career attitudes of first-year veterinary students before and after a required course on veterinary careers. J Vet Med Educ 2014;41:243-52

6. Larkin M. The hidden curriculum: When the college's curriculum says one thing and the culture says another. J Am Vet Med Assoc 2017;250:1062-7.

7. Pritt SL, Case HC. The importance of veterinary career awareness. J Am Vet Med Assoc 2018;252:1200-4.

8. Jelinski MD, Campbell JR, Lissemore K, Miller LM. Demographics and career path choices of graduates from three Canadian veterinary colleges. Can Vet J 2008;49:995-1001.

9. Ilgen DR, Lloyd JW, Morgeson FP, Johnson MD, Meyer CJ, Marrinan M. Personal characteristics, knowledge of the veterinary profession, and influences on career choice among students in the veterinary school applicant pool. J Am Vet Med Assoc 2003;223:1587-94.

10. Heath TJ. Longitudinal study of veterinarians from entry to the veterinary course to ten years after graduation: Career paths. Aust Vet J 2002;80:468-73.

11. Jelinski MD, Campbell JR, Naylor JM, Lawson KL, Derkzen D. Factors affecting the career path choices of graduates at the Western College of Veterinary Medicine. Can Vet J 2008;49:161-6.

12. Morin DE, Molgaard L, Royster E, Johnson-Walker YJ, Fetrow J. Prior experience, career intentions, and post-graduate positions of veterinary students who participated in an 8-week dairy production medicine course. J Vet Med Educ 2019:e1117163r. doi: 10.3138/jvme.1117-163r. [Epub ahead of print].

13. Tyler JW, Larson RL. Assessing veterinary medical education with regard to the attraction, admission, and education of students interested in food supply veterinary medicine and retention of student interest in a career in the food supply sector. J Am Vet Med Assoc 2006;229:922-7.

14. Betsworth DG, Hansen JI. The categorization of serendipitous career development events. J Career Assess 1996;4:91-8.

15. Gwinner K, Andrus D, Prince B. Importance-performance analysis of food-supply veterinary medicine career commitment. J Vet Med Educ 2006;33:525-9.

16. Boyer PE. Creation and evaluation of a food animal curriculum roadmap for veterinary students at the university of Minnesota. J Vet Med Educ 2019;46:555-61.

17. Andrus DM, Gwinner KP, Prince JB. Job satisfaction, changes in 
Kustritz, et al.: Drivers for track change decision-making

occupational area, and commitment to a career in food supply veterinary medicine. J Am Vet Med Assoc 2006;228:1884-93.

18. Klosterman ES, Kass PH, Walsh DA. Approaches to veterinary education - Tracking versus a final year broad clinical experience. Part one: Effects on career outcome. Rev Sci Tech 2009;28:797-810.

19. Walsh DA, Klosterman ES, Kass PH. Approaches to veterinary education - Tracking versus a final year broad clinical experience. Part two: Instilled values. Rev Sci Tech 2009;28:811-22. 